\title{
Do Positive School Experiences and Preference for American Culture Moderate the Association between School-Based Ethnic Discrimination and Mental Health for Filipino American Adolescents?
}

\author{
Tzu-Fen Chang ${ }^{1 *}$, Eun-Jin $\mathrm{Han}^{2}$, Esther E. Onaga ${ }^{1}, \mathrm{M}$. Brent Donnellan ${ }^{3}$ \\ ${ }^{1}$ Department of Human Development and Family Studies, Michigan State University, East Lansing, USA \\ ${ }^{2}$ Department of Social Welfare, Seoul Women's University, Seoul, South Korea \\ ${ }^{3}$ Department of Psychology, Michigan State University, East Lansing, USA \\ Email: "changtz4@msu.edu
}

Received August $7^{\text {th }}, 2013$; revised September $8^{\text {th }}, 2013$; accepted October $6^{\text {th }}, 2013$

Copyright $₫ 2013$ Tzu-Fen Chang et al. This is an open access article distributed under the Creative Commons Attribution License, which permits unrestricted use, distribution, and reproduction in any medium, provided the original work is properly cited.

\begin{abstract}
This study examines short-term and longitudinal associations between school-based discrimination and mental health, (i.e., self-esteem and depression) and the moderating roles of "preference for American culture" and positive school experiences, for 684 Filipino American adolescents drawn from the Children of Immigrants Longitudinal Study (CILS). Our findings suggest that school-based discrimination predicted increased levels of depression and lower levels of self-esteem in short-term but not in long-term. The shortterm negative associations between discrimination and mental health were not moderated by levels of preference for American culture, and positive school experiences decrease the negative association between discrimination and self-esteem. Implications from this study are discussed.
\end{abstract}

Keywords: Filipino American Adolescents; Discrimination; Mental Health; Cultural Preference; School Experiences

\section{Introduction}

Filipino American adolescents are underrepresented in the mental health literature (David \& Okazaki, 2006; Nadal, 2009), even though Filipino Americans are the third-largest Asian American ethnic group in the US, totaling 2.56 million individuals (US Census, 2010). Despite the large number of Filipino Americans residing in the US, they are frequently described as the "invisible minorities" (Cimmarusti, 1996). Filipino Americans experience higher rates of perceived ethnic discrimination than other major Asian American ethnic groups (Gee, Spencer, Chen, Yip, \& Takeuchi, 2007) and are under represented in mental health research. Gee and colleagues (2009) link mental health outcomes with perceived discrimination experiences. However, there has been little investigation on the short-term and long-term mental health consequences of these negative experiences on Filipino Americans. In addition, little is known about acculturation or school experience roles as moderators of perceived discrimination on the short-term and longterm mental health of this group. This paper addresses these research gaps through data drawn from the Children of Immigrants Longitudinal Study (CILS; Portes \& Rumbaut, 19912006).

Prior research using the CILS data examined mental health by examining two key cognitive and affective dimensions of

\footnotetext{
${ }^{*}$ Corresponding author.
}

psychosocial adaptation - self-esteem and depression. Rumbaut (1997) found that among all different nationalities examined in Wave I (1992) of the CILS, only the Filipinos (and Vietnamese) showed statistically significant lower self-esteem scores. They also showed higher depression scores, especially among the female students.

The CILS dataset offers the opportunity to examine longitudinal associations between perceived discrimination and mental health. We targeted school-based experiences because ethnic discrimination is prevalent among Asian American children in this setting (Gee et al., 2009). The study investigates the moderating effects of "preference for American culture" (one of the major indicators of acculturation) and school experiences on both short-term and long-term associations between discriminatory experiences and mental health. Investigating whether these factors moderate mental health outcomes (both short-term and long-term) would render valuable, practical interventions with this population.

\section{Literature Review}

\section{Filipino Americans}

Filipino Americans are distinctive from other Asian American groups because "they are the only Asian American group that experienced direct American colonization" (David \& Okazaki, 2006: p. 5). With this history of colonization, first and se- 
cond generation Filipino Americans have a deep connection with American culture and possess English skills (Nadal, 2009), which leads to an underlying assumption that Filipino Americans can more easily adapt to and acculturate into the American society than other Asian Americans of similar generational groups. On the contrary, scholars have noted that the assumption based on their distinctive history is likely to mask true adjustment difficulties (Gee et al., 2009; Rumbaut, 1996; Wolf, 1997). For example, in a large-scale immigrant survey (Rumbaut, 1996), two-thirds of the Filipino adolescent respondents reported perceiving ethnic discrimination. The 2007 California Health Interview Survey also showed that almost half of Filipinos experienced less respect due to their race or accent in their speech in the past year and $50 \%$ of the discrimination within their lifetime occurred in educational settings (as cited in Gee et al., 2009).

\section{Ethnic Discrimination and Mental Health in Filipino American Adolescents}

Exposure to ethnic discrimination can produce multiple detrimental effects on ethnic minority adolescents' mental health, such as depression, low self-esteem, low self-efficacy, and anxiety (Gee et al., 2009). Few studies have examined the Filipino adolescent population in this area. Rumbaut (1996) found that Filipino adolescents who experienced ethnic discrimination were more susceptible to depressive symptoms. In an in-depth quailtative study, Wolf (1997) suggests that experiences of ethnic discrimination and inequality account for why some Filipino American adolescents suffer from psychological maladjustment (e.g., anxiety and depression) that further leads to increased suicidal ideation.

Prior research did not pay much attention to the long-term associations between ethnic discrimination and mental health among Filipino adolescents, with the exception of Ying and Han's (2006) study in which they found that current perception of school-based ethnic discrimination, and not past school-based experiences of discrimination, predicted levels of depression.

Some features distinguish our study from Ying and Han's study. First, we examined the associations of ethnic discrimination not only with depression but also with self-esteem in shortand long-term outcomes. Second, while Ying and Han's (2006) study examined school-based discrimination on middle adolescence $\left(M_{\text {age }}=14.12\right.$ years $)$, we examined this phenomenon for late adolescence $\left(M_{\mathrm{age}}=17.13\right.$ years). Third, our study examined the role of potential moderators, i.e., preference for American culture (one of the major indicators of acculturation) and school experiences, for associations of discrimination with depression and self-esteem.

\section{Acculturation as a Moderator}

Empirical findings have been mixed regarding whether hostculture orientation serves as a buffer or an exacerbator in moderating the negative associations between discrimination and mental health of ethnic minority adolescents. One line of research suggests that higher levels of orientation toward the host culture alleviate the negative associations between discrimination and mental health, e.g., less depression among Somali male adolescent refugees (Ellis et al., 2010) and higher self-esteem among American Indian female adolescents (Galliher, Jones, \&
Dahl, 2010). This line of research can be interpreted with the lens of social identity theory (Turner, Brown, \& Tajfel, 1979), in which holding a positive view toward a particular social group can contribute to strong identification with the group and further benefit psychological or externalized functioning. Accordingly, individuals with ahigh orientation toward the host culture might be less susceptible to the harm of ethnic discrimination given that they can easily seek social resources/supports of the host society to counteract these discriminatory encounters.

Another line of research based on cognitive dissonance theory (Festinger, 1957) resulted in opposite findings. This theory posits that two discordant cognitions can expose individuals to psychological maladjustment. Based on this theory, adolescents who are highly oriented toward the host culture but also feel discriminated are likely to produce two competing cognitions: They are insiders due to high acculturation versus they are foreigners due to discrimination. The two dissonant beliefs can aggravate adolescents' psychological maladjustment as shown by findings of Latino and Chinese American adolescents studies (Brenner \& Kim, 2009; Umanã-Taylor \& Updegraff, 2007).

To our understanding, no research thus far has focused on acculturation as a moderator for Filipino American adolescents. Doing so would therefore be worthy to enhance our understanding on whether high orientation toward the host culture plays as a protector or an exacerbator in moderating associations between discrimination and mental health for Filipino population. This looks at one indicator of acculturation-preference for American culture measured in this dataset.

\section{School Experiences as a Moderator}

The integrative model on developmental competencies of minority children highlights children's experiences in a microsystem, such as in school (Garcia et al., 1996). Our focus is then on whether the school environment conveys friendly messages and experiences for minority children, positively influencing their psychosocial and behavioral development. The adolescents' perceptions of having positive school experiences (e.g., school safety, a good learning environment, and positive peer/teacher relations) benefit Asian American adolescents' mental health, e.g., less depression, less social stress and anxiety, and higher self-esteem (Lei, 2003; Way \& Robison, 2003). An analysis of the data drawn from the CILS also reveals that youths attending schools they perceived as unsafe displayed significantly lower self-esteem and higher depressive symptoms compared to those attending schools they perceived as safe (Rumbaut, 2005). Other research shows that these positive perceptions of the school environment might mitigate Asian American children's perceptions of negative encounters of discrimination and racism due to their minority status (Lee, 2003). However, no research has yet examined whether positive school experiences can mitigate the negative associations between ethnic discrimination and mental health in Filipino Americans. This study is directed to narrow this research gap by examining the moderating effect of school experiences, i.e., students' perceptions of school safety and learning environment.

\section{Hypotheses}

Several hypotheses are tested in this paper. First, schoolbased discrimination, both past (at Wave I) and current (at 
Wave II), would significantly predict increased levels of depression and lower levels of self-esteem in Filipino American adolescents. Several studies on ethnic minority children have shown that exposure to discrimination can predict poor mental health, e.g., more depression and low self-esteem among Chinese Americans (Juang \& Cookston, 2009) and African Americans (Brody et al., 2006) in both short-term and long-term.

Previous findings on ethnic minority children have been mixed with respect to the moderating effects of preference for American culture (e.g., Benner \& Kim, 2009; Ellis et al., 2010; Galliher et al., 2010; Umanã-Taylor \& Updegraff, 2007). Thus we do not postulate whether levels of preference act as a buffer or as an exacerbator for either short-term or long-term associations of discrimination with levels of depression and self-esteem.

With respect to the moderating effects of school experiences, due to the protective roles played by positive school environments, we hypothesized that positive school experiences would buffer the negative associations of discrimination with depression and self-esteem. Specifically, positive school experiences would (a) decrease the positive associations of both past and current discrimination with levels of depression; and (b) decrease the negative associations of both past and current discrimination with levels of self-esteem.

\section{Method}

\section{Participants}

The Children of Immigrants Longitudinal Study (CILS; Portes \& Rumbaut, 1991-2006) data examined adjustment processes of first and second generation immigrants with origins from Asia and Latin America in three Waves. In the Wave I, adolescents in 8th and 9th grades from all public and private schools in San Diego and Miami were recruited. Recruitment criteria included adolescents born in the United States who had at least one parent born abroad and those who were foreign-born and have resided in the United States for at least five years. The total sample consisted of 5262 adolescents at Wave I and 4288 adolescents $(81.5 \%$ of the original sample) at the Wave II. Wave III involved a sample that reached early adulthood, with an average age of 24 years of age, but this study examined only data collected at Waves I and II.

At Wave I, 819 Filipino American adolescents participated in the CILS, and 724 of the original adolescents participated in the follow-up study at Wave II. The majority of respondents (98.7\%) were drawn from San Diego at Wave I. This study analyzed only those participating in the follow-up study and those reporting depression, self-esteem, and school-based discrimination experiences at both Waves, yielding the final sample of 676 adolescents. Of the sample, the proportion of males $(50.1 \%)$ and females $(49.9 \%)$ were almost equal. At Wave I, their mean age was 14.13 years $(S D=.78)$ and their mean grade level was $8.54(S D=.50)$. Over half of the participants $(57.3 \%)$ were born in the United States, 38.4\% were born in Philippines, while the rest $(4.3 \%)$ were born in other countries (e.g., in Europe or Asia). Those born in Philippines or in other countries were collapsed into the category of first generation, while those born in the United States were second generation. The average age of migration for the first-generation participants was 6.70 years $(S D=4.67)$. With respect to socioeconomic status (SES), $3.2 \%$ were wealthy, $45.4 \%$ were upper-middle class, $39.5 \%$ were lower-middle class, $10.6 \%$ were working-class, $.3 \%$ were poor, and the remaining $(1 \%)$ were missing. SES was reported by adolescents at Wave I. For parental education, 33.7\% of fathers and $26.9 \%$ of mothers received a high school degree or below, while $56.6 \%$ of fathers and $63.8 \%$ of mothers were universityeducated or beyond. The remaining parents $(9.7 \%$ of fathers and $9.3 \%$ of mothers) did not report their educational level.

\section{Measures}

Depression. Depression was measured by four items from Center for Epidemiological Studies-Depression Scales (CES-D; Radloff, 1977) for Wave I and Wave II. These items included: How often have you felt this way during the past week? "I felt sad", "I could not get going", "I didn't feel like eating; my appetite was poor", and "I felt depressed". Responses were scored on a 4-point scale on which: $0=$ rarely; $1=$ some of the time; 2 = occasionally; $3=$ most of the time. The four items were summed and averaged to yield the mean level of depression. The alpha reliability of this scale was .74 at Wave I and .76 at Wave II. The reliability and validity of the CESD-4 have been found to be sufficient in comparison with the full 20-item CESD (Melchior, Huba, Brown, \& Reback, 1993).

Self-Esteem. In both Waves, levels of self-esteem were measured by Rosenberg's Self-Esteem scale (1979) with ten items. Examples of items were as follows: "I am a person of worth", "I do things as well as other people", and "I do not have much to be proud of". Responses were scored on a 4-point scale on which: $0=$ disagrees a lot; $1=$ disagrees a little; $2=$ agrees a little; 3 = agrees a lot. Five items were worded negatively and five items were worded positively. We reverse-weighted the negatively phrased items, and summed and averaged all the items to yield the mean level of self-esteem. The alpha reliability of this scale in the present study was .81 at Wave I and .84 at Wave II.

School-Based Discrimination. School-based discrimination included three kinds of discrimination in school settings: teacher discrimination, peer discrimination, and counselor discrimination. In both waves, adolescents answered the question: "Have you ever felt discriminated against by teachers?" Similarly, adolescents separately responded to the questions related to "whether you have ever felt discriminated against by peers" and "whether you have ever felt discriminated against by counselors." Each response was coded as dichotomous variables $(0$ $=$ No and $1=$ Yes) and then summed. School-based ethnic discrimination score was based on the study conducted by Ying and Han (2006).

Preference for American Culture. Orientation toward the host society was assessed by levels of preference for doing things the American way as reported at Wave II. Adolescents only answered one question: "How often do you prefer American ways of doing things?" This item was scored on a 4-point scale on which: $0=$ never, $1=$ sometimes, $2=$ most of the time, and $3=$ all the time. One study using the CILS data identified this item as the indicator of levels of acculturation (Ying \& Han, 2007). In this study, we focus on this indicator of acculturation.

School Experiences. At Wave II, school experiences measured participants' perceptions of school safety and the learning environment. The results of the factor analysis indicated the two-dimensional structure of the perceived school experiences scale. The first extracted factor was correlated with items assessing school discipline, grading fairness, and teachers' attitudes. The second extracted factor was highly correlated with 
three items: "Don't feel safe in school" $(r=.52, p<.001)$, "Students disruptions prevent learning" $(r=.53, p<.001)$, and "Many gangs in school" $(r=.55, p<.001)$. This study focuses on the second factor. Responses were scored on a 4-point scale on which: $0=$ disagrees a lot; $1=$ disagrees a little; 2 agrees a little; 3 = agrees a lot. The scores of all items were reversely coded for further analyses and convenience of interpretation. All the items were summed and averaged to yield the mean level of school experiences. Higher scores represent more positive school experiences. The alpha reliability of this scale in the present study was .54 .

\section{Results}

Descriptive statistics are presented in Table 1. Participants reported low levels of depression and school-based discrimination at Waves I and II, as indicated by scores below midpoint of item range. Participants reported high levels of self-esteem at both waves and high levels of preference for American culture, as indicated by scores beyond midpoint of item range. Their school experiences were moderately positive given that the mean was close to the midpoint of item range.

\section{Analyses}

Before testing the study hypotheses, we explored the relations between demographic variables and the study variables. Compared to the male adolescents, the female adolescents reported higher levels of depression at Wave I and Wave II $(t \mathrm{~s}(674)=6.21$ and $5.49, p \mathrm{~s}<.001$ and .001 , respectively $)$, lower levels of self-esteem at Wave I and Wave II $(t \mathrm{~s}(674)=$ 3.62 and $2.15, p \mathrm{~s}<.001$ and $=.034$, respectively), and more positive school experiences at Wave II $(t(674)=2.44, p=.014)$. Compared to the first-generation adolescents, the second-generation adolescents reported higher levels of preference for American culture at Wave II $(t(674)=2.68, p=.008)$. Grade point average (GPA) was significantly and positively correlated with levels of self-esteem at Wave I and Wave II $(r \mathrm{~s}(674)=.25$ and $.16, p \mathrm{~s}<.001$ and .001 , respectively) and school experiences at Wave II $(r(674)=.14, p<.001)$. Based on prior research (Umanã-Taylor \& Updegraff, 2007) and initial analyses,

Table 1.

Descriptive statistics of the major variables.

\begin{tabular}{ccccc}
\hline & \multicolumn{5}{c}{ Range } \\
\hline Variable & $M$ & $S D$ & Potential & Actual \\
\hline Depression WI & .67 & .63 & $0-3$ & $.0-3.0$ \\
Depression WII & .72 & .65 & $0-3$ & $.0-3.0$ \\
Self-esteem WI & 2.26 & .49 & $0-3$ & $.40-3.0$ \\
Self-esteem WII & 2.42 & .51 & $0-3$ & $.80-3.0$ \\
$\begin{array}{c}\text { School-based } \\
\text { discrimination WI }\end{array}$ & .57 & .77 & $0-3$ & $.0-3.0$ \\
$\begin{array}{c}\text { School-based } \\
\text { discrimination WII }\end{array}$ & .70 & .87 & $0-3$ & $.0-3.0$ \\
$\begin{array}{c}\text { Preference for American } \\
\text { culture at WII }\end{array}$ & 2.14 & .89 & $0-3$ & $.0-3.0$ \\
$\begin{array}{c}\text { School experiences WII } \\
\text { Sch }\end{array}$ & 1.67 & .68 & $0-3$ & $.0-3.0$ \\
\hline
\end{tabular}

regression analyses controlled for covariates including gender, generational status, GPA, age, and SES. SES is the unit-weighted standardized scale as created by Portes and Rumbaut (19912006). We used single dummy codes for gender $(1=$ female $)$ and generational status ( 1 = first generation). In addition, when examining the discrimination-adjustment link, prior research controlled for the past levels of adjustment (Benner \& Kim, 2009; Brody et al., 2006). Thus, to test associations between past or current discriminatory experiences and depression and self-esteem, respective levels at Wave I were controlled.

Four separate hierarchical multiple regression analyses examined the associations of past and current school-based discrimination with depression and self-esteem. Four regression models were implemented for each regression analysis. In Model 1, we entered the previously-mentioned controlled variables. Model 2 tested associations of past or current school-based discrimination with mental health at Wave II, given that covariates were statically controlled. To test associations of past discriminatory experiences with depression and self-esteem, school-based discrimination at Wave I was entered. To test associations of current discriminatory experiences with depression and selfesteem, school-based discrimination at Wave II was entered. In Model 3, preference for American culture and school experiences were entered as a block. Model 4 tested moderating effects of preference for American culture and school experiences on links between discrimination and mental health.

To test associations of past discriminatory experiences withdepression and self-esteem, two interactions were entered as a block: school-based discrimination at Wave I by preference for American culture and school-based discrimination at Wave I by school experiences. To test associations of current discriminatory experiences with depression and self-esteem, two interactions were entered as a block: school-based discrimination at Wave II by preference for American culture and school-based discrimination at Wave II by school experiences.

Based on Cohen and colleagues' recommendations (2003), school-based discrimination Waves I and II, preference for American culture at Wave II, and school experiences at Wave II were centered on their means to decrease multicollinearity. $\Delta R^{2}$ and $F_{\text {change }}$ were computed between the main-effect model (Model 3) and the moderator model (Model 4). For the interaction model (i.e., Model 4), $\Delta R^{2}$ and its level of significance provided information on what percentage of additional variance interaction effects accounted for depression and self-esteem at Wave II. When $\Delta R^{2}$ of any model was not significant, the following model was not conducted.

\section{Test of Associations between Past School-Based Discrimination and Mental Health}

Association between School-Based Discriminatory Experiences at Wave I and Depression at Wave II. Results are shown in Table 2. In Model 1, levels of depression at Wave II was positively and significantly predicted by levels of depression at Wave I $(\beta=.30, p<.001)$, gender (being female) $(\beta=.17, p$ $<.001)$, and SES $(\beta=.10, p=.009)$, but was negatively and significantly predicted by GPA $(\beta=-.10, p=.008)$. Contrary to our hypothesis, school-based discrimination with covariates controlled did not significantly predict depression at Wave II (see Model 2). The long-term association between school-based discrimination and depression was not significant. Because $\Delta R^{2}$ 
Table 2.

Hierarchical multiple regression testing the associations of school-based discrimination at Wave I with depression at Wave II and self-esteem at Wave II.

\begin{tabular}{|c|c|c|c|c|}
\hline & Model 1 & & Model 2 & \\
\hline Variable & $B(S E)$ & $\beta$ & $B(S E)$ & $\beta$ \\
\hline \multicolumn{5}{|c|}{ Outcome variable: Depression at Wave II } \\
\hline Depression at Wave I & $.31^{* * *}(.04)$ & .30 & $.31^{* * *}(.04)$ & .30 \\
\hline Gender $(1=$ female $)$ & $.22^{* * *}(.05)$ & .17 & $.22^{* * *}(.05)$ & .17 \\
\hline Age & $-.02(.03)$ & -.03 & $-.02(.03)$ & -.03 \\
\hline SES & $.13^{* *}(.05)$ & .10 & $.13^{* *}(.05)$ & .10 \\
\hline Generational status $(1=$ first generation $)$ & $.06(.05)$ & .05 & $.06(.05)$ & .05 \\
\hline GPA & $-.08^{* *}(.03)$ & -.10 & $-.08^{* *}(.03)$ & -.10 \\
\hline School-based discrimination at Wave I & & & $-.02(.03)$ & -.02 \\
\hline Intercept & .65 & & .67 & \\
\hline$F$ & $19.71^{* * *}$ & & $16.92^{* * *}$ & \\
\hline $\mathrm{R}^{2}$ & .15 & & .15 & \\
\hline$F_{\text {change }}$ & & & .35 & \\
\hline$\Delta \mathrm{R}^{2}$ & & & .00 & \\
\hline \multicolumn{5}{|c|}{ Outcome variable: Self-esteem at Wave II } \\
\hline Self-esteem at Wave I & $.39^{* * *}(.04)$ & .38 & $.39^{* * *}(.04)$ & .38 \\
\hline Gender $(1=$ female $)$ & $-.06(.04)$ & -.06 & $-.06(.04)$ & -.06 \\
\hline Age & $.00(.02)$ & .00 & $.00(.02)$ & .00 \\
\hline SES & $-.05(.04)$ & -.05 & $-.05(.04)$ & -.05 \\
\hline $\begin{array}{l}\text { Generational status } \\
(1=\text { first generation })\end{array}$ & $.05(.04)$ & .05 & $.05(.04)$ & .05 \\
\hline GPA & $.06^{*}(.02)$ & .09 & $.06^{*}(.02)$ & .09 \\
\hline School-based discrimination at Wave I & & & $-.01(.02)$ & -.01 \\
\hline Intercept & $1.49^{* * *}$ & & $1.50^{* * *}$ & \\
\hline$F$ & $23.45^{* * *}$ & & $20.08^{* * *}$ & \\
\hline$R^{2}$ & .17 & & .17 & \\
\hline$F_{\text {change }}$ & & & .07 & \\
\hline$\Delta R^{2}$ & & & .00 & \\
\hline
\end{tabular}

Note: ${ }^{*} p<.05 .{ }^{* *} p<.01 .{ }^{* * *} p<.001$ (two-tailed tests).

of Model 2 was not significant, we did not conduct the following regressions to test moderating effects of preference for American culture and school experiences.

Association between school-based discriminatory experiences at Wave I and self-esteem at Wave II. Results are shown in Table 2. In Model 1, levels of self-esteem at Wave I ( $\beta=.38$, $p<.001)$ and GPA $(\beta=.09, p=.015)$ positively and significantly predicted levels of self-esteem at Wave II. Contrary to our hypothesis, school-based discrimination at Wave I with controlled covariates did not significantly predict self-esteem at Wave II (see Model 2). The long-term association between school-based discrimination and self-esteem was not signifi- cant. Because $\Delta R^{2}$ of Model 2 was not significant, we did not conduct the following regressions to test moderating effects of preference for American culture and school experiences.

\section{Associations between Current School-Based Discrimination and Mental Health and Moderating Effects}

Association between Current School-Based Discriminatory Experiences at Wave II and Depression at Wave II. Results are shown in Table 3. Model 1 results were the same as those shown in Model 1 to test the association between past school- 
based discrimination and depression at Wave II. In Model 2, school-based discrimination at Wave II $(\beta=.16, p<.001)$ with controlled covariates positively and significantly predicted depression at Wave II (see Table 3). This finding was consistent with our hypothesis that the short-term, school-based discrimination significantly predicted higher levels of depression.

Model 3 shows that levels of depression at Wave II were negatively and significantly predicted by school experiences at

Table 3.

Hierarchical multiple regression testing the associations of school-based discrimination at Wave II with depression at Wave II and self-esteem at Wave II.

\begin{tabular}{|c|c|c|c|c|c|c|c|c|}
\hline & Model 1 & & Model 2 & & Model 3 & & Model 4 & \\
\hline variable & $B(S E)$ & $\beta$ & $B(S E)$ & $\beta$ & $B(S E)$ & $\beta$ & $B(S E)$ & $\beta$ \\
\hline \multicolumn{9}{|c|}{ Outcome variable: Depression at Wave II } \\
\hline Depression at Wave I & $.31^{* * *}(.04)$ & .30 & $.30^{* * *}(.04)$ & .29 & $.27^{* * *}(.04)$ & .27 & $.28^{* * *}(.04)$ & .27 \\
\hline Gender $(1=$ female $)$ & $.22^{* * *}(.05)$ & .17 & $.23^{* * *}(.05)$ & .18 & $.25^{* * *}(.05)$ & .19 & $.25^{* * *}(.05)$ & .19 \\
\hline Age & $-.02(.03)$ & -.03 & $-.02(.03)$ & -.02 & $-.02(.03)$ & -.03 & $-.02(.03)$ & -.02 \\
\hline SES & $.13^{* *}(.05)$ & .10 & $.14^{* *}(.05)$ & .10 & $.13^{* *}(.05)$ & .10 & $.13^{* *}(.05)$ & .10 \\
\hline Generational status $(1=$ Foreign-Born $)$ & $.06(.05)$ & .05 & $.06(.05)$ & .04 & $.05(.05)$ & .04 & $.04(.05)$ & .03 \\
\hline GPA & $-.08^{* *}(.03)$ & -.10 & $-.09^{* *}(.03)$ & -.11 & $-.07^{*}(.03)$ & -.09 & $-.08^{* *}(.03)$ & -.10 \\
\hline SD at Wave II & & & $.12^{* * *}(.03)$ & .16 & $.11^{* * *}(.03)$ & .12 & $.11^{* * *}(.03)$ & .14 \\
\hline PAC & & & & & $.03(.04)$ & .03 & $.04(.04)$ & .04 \\
\hline $\mathrm{SE}$ & & & & & $-.15^{* * *}(.03)$ & -.16 & $-.15^{* * *}(.03)$ & -.16 \\
\hline SD at Wave II $\times$ PAC & & & & & & & $.06(.04)$ & .05 \\
\hline $\mathrm{SD}$ at Wave II $\times \mathrm{SE}$ & & & & & & & $-.01(.04)$ & -.01 \\
\hline Intercept & .65 & & .50 & & .78 & & .73 & \\
\hline$F$ & $19.71^{* * *}$ & & $20.29^{* * *}$ & & $18.47^{* * *}$ & & $15.27^{* * *}$ & \\
\hline$R^{2}$ & .15 & & .18 & & .20 & & .20 & \\
\hline$F_{\text {change }}$ & & & $20.36^{* * *}$ & & $10.16^{* * *}$ & & .91 & \\
\hline$\Delta R^{2}$ & & & .03 & & .02 & & .00 & \\
\hline \multicolumn{9}{|c|}{ Outcome variable: Self-Esteem at Wave II } \\
\hline Self-esteem at Wave I & $.39^{* * * *}(.04)$ & .38 & $.39^{* * *}(.04)$ & .39 & $.38^{* * *}(.04)$ & .37 & $.38^{* * *}(.04)$ & .37 \\
\hline Gender $(1=$ female $)$ & $-.06(.04)$ & -.06 & $-.06^{+}(.04)$ & -.06 & $-.08^{*}(.04)$ & -.07 & $-.08^{*}(.04)$ & -.08 \\
\hline Age & $.00(.02)$ & .00 & $-.01(.02)$ & -.01 & $.00(.02)$ & .00 & $.00(.02)$ & .00 \\
\hline SES & $-.05(.04)$ & -.05 & $-.06(.04)$ & -.05 & $-.05(.04)$ & -.05 & $-.06(.04)$ & -.05 \\
\hline Generational status $(1=$ Foreign-Born $)$ & $.05(.04)$ & .05 & $.05(.04)$ & .05 & $.06(.04)$ & .06 & $.06(.04)$ & .06 \\
\hline GPA & $.06^{*}(.02)$ & .09 & $.06^{*}(.02)$ & .10 & $.05^{*}(.02)$ & .08 & $.06^{*}(.02)$ & .09 \\
\hline SD at Wave II & & & $-.08^{* * *}(.02)$ & -.14 & $-.07^{* * *}(.02)$ & -.12 & $-.07^{* * *}(.02)$ & -.11 \\
\hline PAC & & & & & $-.03(.03)$ & -.03 & $-.02(.03)$ & -.02 \\
\hline $\mathrm{SE}$ & & & & & $.12^{* * *}(.03)$ & .17 & $.12^{*}(.03)$ & .16 \\
\hline $\mathrm{SD}$ at Wave II $\times \mathrm{PAC}$ & & & & & & & $.02(.03)$ & .02 \\
\hline SD at Wave II $\times$ SE & & & & & & & $.07^{*}(.03)$ & .08 \\
\hline Intercept & $1.49^{* * *}$ & & $1.58^{* * *}$ & & $1.40^{* * *}$ & & $1.41^{* * *}$ & \\
\hline$F$ & $23.45^{* * *}$ & & $22.98^{* * *}$ & & $20.97^{* * *}$ & & $17.82^{* * *}$ & \\
\hline$R^{2}$ & .17 & & .19 & & .22 & & .23 & \\
\hline$F_{\text {change }}$ & & & $16.87^{* * *}$ & & $11.40^{* * * *}$ & & $3.07^{*}$ & \\
\hline$\Delta R^{2}$ & & & .02 & & .03 & & .01 & \\
\hline
\end{tabular}

Note: $\mathrm{SD}=$ School-based Discrimination; $\mathrm{PAC}=$ Preference for American Culture; $\mathrm{SE}=$ School Experiences. ${ }^{+} p<.10 .{ }^{*} p<.05 .{ }^{* *} p<.01 .{ }^{* * *} p<.001$ (two-tailed tests). 
Wave II $(\beta=-.16, p<.001)$, but not by preference for American culture at Wave II. This result suggests that current positive school experiences were related to less depression. In Model 4, the school-based discrimination at Wave II by preference for American culture interaction effect and the school-based discrimination at Wave II by school experiences interaction effect were not significant. These findings reveal that levels of preference for American culture and school experiences did not moderate short-term association between discrimination and depression.

Association between Current School-Based Discriminatory Experiences at Wave II and Self-Esteem at Wave II. Results are shown in Table 3. The results of Model 1 were the same as those shown in Model 1 in the analyses testing the association between past school-based discrimination and self-esteem at Wave II. In Model 2, school-based discrimination at Wave II ( $\beta$ $=-.14, p<.001)$ negatively and significantly predicted levels of self-esteem at Wave II. This finding was consistent with our hypothesis that the short-term school-based discrimination significantly predicted lower levels of self-esteem.

Model 3 shows that levels of self-esteem at Wave II were positively and significantly predicted by school experiences at Wave II $(\beta=.17, p<.001)$, but not by preference for American culture at Wave II. This result suggests that current positive school experiences were related to increased self-esteem. In Model 4, the school-based discrimination at Wave II by preference for American culture interaction effect was not significant and the school-based discrimination at Wave II by school experiences interaction effect was significant $(\beta=.08, p=.013)$. $\Delta \mathrm{R}^{2}$ and $F_{\text {change }}$ were significant between Model 3 and Model 4 $\left(\Delta \mathrm{R}^{2}=.01 ; F_{\text {change }}(2,677)=3.07, \mathrm{p}=.042\right)$. This finding indicates that the moderating effect of school experiences accounted for an additional $1.0 \%$ of the variance of self-esteem at Wave II (i.e., the change between Model 3 and Model 4). A further post-hoc analysis revealed that self-esteem at Wave II was negatively related with school-based discrimination at Wave II for children with negative school experiences (1 SD below the mean; $\mathrm{b}=-.19, \mathrm{p}<.001)$, but not for those with positive school experiences (1 SD above the mean; $b=-.03, p=.492$ ) (Figure 1). For Filipino American adolescents, positive school experiences buffered the short-term negative association between discrimination and self-esteem.

\section{Discussion}

Supportive of the initial hypotheses, this study found negative associations between school-based ethnic discrimination and the mental health of Filipino American adolescents in the short-term. This finding corresponds to the positive correlation between current school-based discrimination and levels of depression for Filipino American adolescents found by Ying and Han (2006), albeit that their target was middle adolescents. This is also consistent with scholars' caution that Filipino Americans' special US colonized circumstances can mask Filipino American adolescents' adjustment challenges of racism and discrimination (Rumbaut, 1996).

The evidence of the short-term link not withstanding, the findings do not suggest the long-term toll from discriminatory experiences upon the mental health of Filipino American adolescents. Findings on other ethnic minority adolescents show similar results. For instance, in a study on Chinese Americans (Benner \& Kim, 2009), past experiences of long-term discrimi-

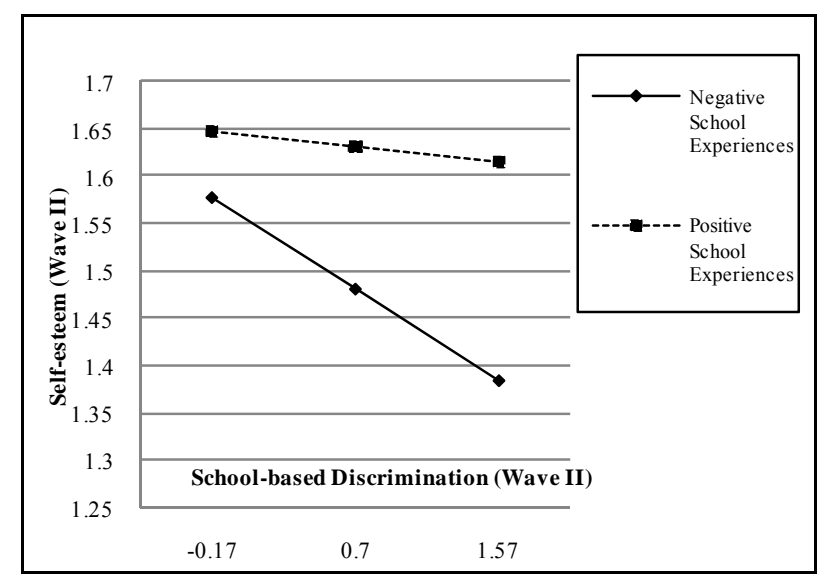

Figure 1.

Interaction effect between school-based discrimination at wave ii and school experiences at Wave II and self-esteem at Wave II as the outcome variable; Note. $B=$ unstandardized regression coefficient; $-.17=$ mean $-1 S D ; .70=$ mean; $1.57=$ mean $+1 S D .{ }^{* * *} p<.001$.

nation (reported in middle adolescence) predicted poor school engagement and academic performance but did not lead to increased levels of depression (reported in late adolescence). Another study on male American Indian adolescents suggests that past experiences of discrimination predicted decreased selfesteem (reported two years later) only in a marginal significance level, but are strongly linked with their substance use (Galliher et al., 2010). Taken together, the findings of this study and other literature suggest that the longitudinal harm of ethnic discrimination is less significant to psychological adjustment, but might exact more severe consequences on externalized outcomes (e.g., school performance and engagement or substance use). However, caution is in order when drawing implications of these findings. Although this study showed that past experiences of discrimination do not appear to associate with detrimental effects on long-term mental health of late adolescents, these experiences might emerge as a threatening factor for Filipino Americans' mental health in adulthood. Further research should focus on longitudinal studies tracing associations between past discriminatory experiences and mental health as individuals become younger or older adults.

This study extended the study of Ying and Han (2006) by examining moderating effects of both preference for American culture and school experiences for associations of school-based discrimination with depression and self-esteem for Filipino American adolescents. Our study shows preference for American culture did not moderate the associations between current experiences of school-based discrimination with depression and self-esteem. This finding suggests that school-based discrimination may bring similar levels of negative effects on mental health among Filipino American adolescents with both high and low preference for American culture. This might be explained by their colonial history. Although Filipinos are geographically defined as Asians, they have a unique culture, i.e., being more heavily impacted by Spanish and American colonization than the cultures of other Asian groups (David \& Okazaki, 2006). Due to direct American colonization, first and second generation Filipino Americans bears a colonial mentality whereby their native culture can be denigrated and American culture accorded a superior status (David \& Okazaki, 2006). 
The colonial mentality is prevalent among Filipino Americans and internalized into their cognition (David \& Okazaki, 2006). For example, Filipino Americans commonly hold self-image of "being Americanized". Accordingly, we surmised that Filipino American adolescents might subconsciously or consciously view themselves as being Americanized as important, regardless of their tendencies of acculturation, such as preference for American culture. The cognition of being Americanized conveys a very discordant message against their discriminatory encounters, such as feeling alienated from American peers. The cognitive dissonance theory posits that two discordant cognitions can expose individuals to psychological maladjustment (Festinger, 1957). Based on this theory, the degrees of negative associations between discriminatory experiences and mental health are plausibly similar for Filipino American adolescents, regardless of whether they hold high or low preference for American culture.

Contrary to the research findings of the moderating effect of acculturation on Latino and Chinese Americans (Benner \& Kim, 2009; Umanã-Taylor \& Updegraff, 2007), our study suggests that acculturation exacerbates the negative association between discrimination and mental health. Moreover, our finding was contradictory to the assumption drawn from social identity theory (Turner et al., 1979) and findings on Somali male adolescent refugees (Ellis et al., 2010) and American Indian female adolescents (Galliher et al., 2010), which suggest that acculturation buffers the negative association between discrimination and mental health. We argue that these mixed findings on the moderating role of acculturation (including indicators such as preference for American culture, language usage, and participation of activities) might stem from three different values about acculturation across different ethnic groups. First, some groups may view high acculturation as an access to gain social supports of the host culture against discriminatory experiences. Second, some groups may view acculturation as a proof of being assimilated into the host culture; thus, discrimination and acculturation should be treated as two incompatible cognitions. Third, the colonial mentality such as high self-image of being Americanized is strongly rooted in Filipino Americans' cognition whereby acculturation plays a less important role in moderating the effect of discrimination. Alternatively, the mixed findings may be due to inconsistent measures of acculturation: Umanã-Taylor and Updegraff (2007) and Ellis et al. (2010) assessed behavioral domain, Galliher et al. (2010) and our study assessed cultural preference, and Benner and Kim (2009) assessed both domains and values. Using a consistent measure of acculturation should be conducted in the future.

This study extended previous studies on the protective and buffering role played by positive school experiences for the association between ethnic discrimination and self-esteem. Positive school experiences, i.e., a safe and positive learning environment, were found to alleviate the negative association between school-based discrimination and self-esteem in the shortterm. Research on Asian American adolescents or college students has shown that a positive school environment, including school safety and positive peer/teacher relations, mitigates perceptions of discrimination (Lee, 2003), and protects adolescents from negative associations between discrimination and mental health the negative effects of discrimination on mental health, e.g., depression (in Taiwanese immigrants, Tsai, 2006; in African Americans, Brody et al., 2006). In line with these findings, our study suggests that school safety and a positive learning environment might mitigate the short-term negative association of school-based discriminatory encounters for Filipino American adolescents' mental health. Taken together, the findings from our study and other literature suggest that the overall quality of safe and positive school environment may influence ethnic minority children's perception of negative encounters that occurred in school and thus protect the ethnic minority children's mental health.

One unexpected finding is that adolescents' SES was negatively associated with depression given that other covariates were controlled. This finding is inconsistent with the long established association between low SES and increased risk of depression (e.g., a meta-analysis by Lorant and colleagues, 2003). However, this can be explained by the diminishing returns hypothesis (Farmer \& Ferraro, 2005). This hypothesis posits that compared to Whites, ethnic minorities gain less economic or social-status returns accompanied by high SES. These diminishing returns increase high SES ethnic minorities' awareness of the social and economic inequalities and in turn are detrimental to their mental health. Thus, among ethnic minorities, high SES compared to low SES individuals tend to experience increased risk of depression. Our finding supports this hypothesis.

\section{Limitations and Implications}

Despite providing new insights on the mental health of Filipino American adolescents, this study has some limitations. First, the present study's failure to detect significant long-term associations between ethnic discrimination and mental health might be linked to the nature of the CILS data, i.e., a lapse of three years between Waves I and II, diminishing the strength of the association. Future studies with shortened time points (e.g., one or two years) and assessing more time points would more clearly describe the longitudinal effects of discrimination.

Second, measurement limitation rests on the construct of adolescents' acculturation orientation. In the CILS data, adolescents' acculturation orientation was only assessed by one item measuring preference for American culture. Previous research has revealed that the nature of acculturation is multi-dimensional and multi-faceted (Berry, 2003). The use of only one item cannot reflect the overall picture of acculturation of Filipino American adolescents. This limitation might also explain the failure to capture the moderating effect of acculturation. Future studies should assess Filipino adolescents' acculturation with scales based on a multi-dimensional framework.

Third, we surmised that the failure to detect the moderating effect of preference for American culture is explained by the prevalence of a colonial mentality in the Filipino population, regardless of their levels of acculturation. However, this study could not examine the relation between colonial mentality and acculturation given that the CILS data did not provide any items or scales assessing colonial mentality. In fact, only one study to date attempted to quantify and measure the colonial mentality of Filipino American adolescents (Bergano \& Bergano-Kinney, 1997). Yet, their measure has been questioned with low face validity due to the limited numbers of items (David \& Okazaki, 2006). Future research to develop more valid measures of colonial mentality will clarify its relationship to acculturation. Doing so would better describe the link between colonial mentality and the overall psychological adjustment of the Filipino American adolescents.

Fourth, one statistical issue rests on the extent of statistical 
power for detecting interaction effects. One interaction effect was found, i.e., school-based discrimination at Wave II by school experiences at Wave II, but this study had a low power to detect this interaction $\left(\Delta R^{2}\right.$ was .01$)$. As Cohen et al. (2003) noted, interactions are not easy to be observed in social science research and often explain a small portion of variance over and above first-order effects (i.e., $\Delta R^{2}$ from .01 to .05). Although $\Delta R^{2}$ of this study fell into this range, the interpretation of this significant interaction effect should be interpreted with caution due to the low power.

These limitations notwithstanding, the present study provides useful information on how adults in school settings such as educators and clinicians can assist Filipino American adolescents to overcome the harm of discriminatory experiences. Our research suggests that both highly and lowly acculturated adolescents might be susceptible to negative effects of current school-based ethnic discrimination in the short-term. Educators' and clinicians' support of school and psychological adjustment with all Filipino American adolescents, regardless of their levels of acculturation, becomes critical.

Another implication is that school administrators and teachers play important roles to provide positive school experiences, i.e., a safe and good learning environment for students. Evidence from our study that strong levels of school safety and good learning environment appear to be protective factors against school-based ethnic discrimination suggests that school administrators and teachers have significant roles to support Filipino American adolescents. For example, they can consistently monitor their school for unsafe situations among students (e.g., conflicts between racial/ethnic groups and gang activities) as well as foster a positive learning environment. Facilitating a safe school environment and robust learning experiences can help decrease potential harm of school-based discrimination and further enhance Filipino American adolescents' mental health.

\section{REFERENCES}

Benner, A. D., \& Kim S. Y. (2009). Experiences of discrimination among Chinese American adolescents and the consequences for socioemotional and academic development. Developmental Psychology, 45, 1682-1694. http://dx.doi.org/10.1037/a0016119

Bergano, A. L., \& Bergano-Kinney, B. L. (1997). Images, roles, and expectations of Filipino Americans by Filipino Americans. In M. P. P. Root (Ed.), Filipino Americans: Transformation and identity (pp. 198-207). Thousand Oaks, CA: Sage. http://dx.doi.org/10.4135/9781452243177.n13

Berry, J. W. (2003). Conceptual approaches to acculturation. In K. Chun, P. Balls-Organista, \& G. Martin (Eds.), Acculturation: Advances in theory, measurement, and applied research (pp. 17-37). Washington DC: American Psychological Association Press. http://dx.doi.org/10.1037/10472-004

Brody, G. H., Chen, Y.-F., Murry, V. M., Ge, X., Simons, R. L., Gibbons, F. X., \& Cutrona, C. E. (2006). Perceived discrimination and the adjustment of African American youths: A five-year longitudinal analysis with contextual moderation effects. Child Development, 77 , 1170-1189. http://dx.doi.org/10.1111/j.1467-8624.2006.00927.x

Cimmarusti, R. A. (1996). Exploring aspects of Filipino-American families. Journal of Marital and Family Therapy, 22, 205-217. http://dx.doi.org/10.1111/j.1752-0606.1996.tb00199.x

Cohen, J., Cohen, P., West, S. G., \& Aiken, L. S. (2003). Applied multiple regression/correlation analysis for the behavioral sciences (3rd ed.). Mahwah, NJ: Lawrence Erlbaum.

Cordova, F. (1983). Filipinos: Forgotten Asian Americans. Dubuque, IA: Kendall/Hunt.

David, E. J. R., \& Okazaki, S. (2006). Colonial mentality: A review and recommendation for Filipino American psychology. Cultural Diversity \& Ethnic Minority Psychology, 12, 1-16. http://dx.doi.org/10.1037/1099-9809.12.1.1

Ellis, B. H., MacDonald, H. Z., Klunk-Gillis, J., Lincoln, A., Strunin, L., \& Cabral, H. J. (2010). Discrimination and mental health among Somali refugee adolescents: The role of acculturation and gender. The American Journal of Orthopsychiatry, 80, 564-575. http://dx.doi.org/10.1111/j.1939-0025.2010.01061.x

Espiritu, Y. L., \& Wolf, D. L. (2001). The paradox of assimilation: Children of Filipinoimmigrants in San Diego. In R. G. Rumbaut, \& A. Portes (Eds.), Ethnicities: Children of immigrants in America. Berkeley, CA: University of California Press.

Farmer, M., \& Ferraro, K. (2005). Are racial disparities in health conditional on socioeconomic status? Social Science\& Medicine, 60, 191204. http://dx.doi.org/10.1016/j.socscimed.2004.04.026

Festinger, L. (1957). A theory of cognitive dissonance. Stanford, CA: Stanford University Press

Galliher, R. V., Jones, M. D., \& Dahl, A. (2010). Concurrent and longitudinal effects of ethnic identity and experiences of discrimination on psychosocial adjustment of Navajo adolescents. Developmental Psychology, 47, 509-526. http://dx.doi.org/10.1037/a0021061

García Coll, C., Lamberty, G., Jenkins, R., McAdoo, H. P., Crnic, K. Wasik, B. H., \& Garcia, H. V. (1996). An integrative model for the study of developmental competencies in minority children. Child Development, 67, 1891-1914. http://dx.doi.org/10.2307/1131600

Gee, G. C., Ro, A., Shariff-Marco. S., \& Chae, D. (2009). Racial discrimination and health among Asian Americans: Evidence, assessment, and directions for future research. Epidemiologic Review, 31, 130151. http://dx.doi.org/10.1093/epirev/mxp009

Juang, L. P., \& Cookston, J. T. (2009). Acculturation, discrimination, and depressive symptoms among Chinese American adolescents: A longitudinal study. The Journal of Primary Prevention, 30, 475-496. http://dx.doi.org/10.1007/s10935-009-0177-9

Lee, R. M. (2003). Do ethnic identity and other-group orientation protect against discrimination for Asian Americans? Journal of Counseling Psychology, 50, 133-141. http://dx.doi.org/10.1037/0022-0167.50.2.133

Lei, J. L. (2003). (Un)Necessary toughness?: Those "Loud Black Girls" and those "Quiet Asian Boys". Anthropology and Education Quarterly, 34, 158-181. http://dx.doi.org/10.1525/aeq.2003.34.2.158

Lorant, V., Deliege, D., Eaton, W., Robert, A., Philippot, P., \& Ansseau, M. (2003). Socioeconomic inequalities in depression: A meta-analysis. American Journal of Epidemiology, 157, 98-112. http://dx.doi.org/10.1093/aje/kwf182

Melchior, L. A., Huba, G. J., Brown, V. B., \& Reback, C. J. (1993). A short depression index for women. Educational and Psychological Measurement, 53, 1117-1125. http://dx.doi.org/10.1177/0013164493053004024

Nadal, K. L. (2009). Filipino American psychology: A handbook of theory, research, and clinical practice. Bloomington, IN: Authorhouse.

Portes, A., \& Rumbaut, R. G. (2008). Children of Immigrants Longitudinal Study (CILS), 1991-2006 [Computer file]. ICPSR20520-v1. Bibliographic Citation: Ann Arbor, MI: Inter-University Consortium for Political and Social Research [distributor], 2008-01-07. http://dx.doi.org/10.3886/ICPSR20520

Radloff, L. (1977). The CES-D scale: A self report depressions scale for research in the general population. Applied Psychological Measurement, 1, 385-401. http://dx.doi.org/10.1177/014662167700100306

Rosenberg, M. (1979). Components of Rosenberg's self-esteem scale. Conceiving the self. New York: Basic Books.

Rumbaut, R. G. (1996). The crucible within: Ethnic identity, self-esteem, and segmented assimilation among children of immigrants. In A. Portes (Ed.), The new second generation (pp. 119-170). New York: Russell Sage.

Rumbaut, R. G. (1997). Achievement and ambition among children of immigrants in Southern California. Working Paper No. 215. Annandale-on-Hudson, NY: The Jerome Levy Economics Institute of Bard College.

Rumbaut, R. G. (2005). Turning points in the transition to adulthood: Determinants of educational attainment, incarceration, and early child- 
bearing among children of immigrants. Ethnic and Racial Studies, 28, 1041-1086. http://dx.doi.org/10.1080/01419870500224349

Tsai, J. H. (2006). Xenophobia, ethnic community, and immigrant youths' friendship network formation. Adolescence, 41, 285-298.

Turner, J. C., Brown, R. J., \& Tajfel, H. (1979). Social comparison and group interest in in-group favouritism. European Journal of Social Psychology, 9, 187-204.

http://dx.doi.org/10.1080/01419870500224349

Umanã-Taylor, A., \& Updegraff, K. A. (2007). Latino adolescents' mental health: Exploring the interrelations among discrimination, ethnic identity, cultural orientation, self-esteem, and depressive symptoms. Journal of Adolescence, 30, 549-567.

http://dx.doi.org/10.1016/j.adolescence.2006.08.002

US Census Bureau (2010). Profile of general population and housing characteristics: 2010 demographic profile data.

http://factfinder2.census.gov/faces/tableservices/jsf/pages/productvie w.xhtml?pid=DEC 10 DP DPDP1

Way, N., \& Robinson, M. G. (2003). A longitudinal study of the effects of family, friends, and school experiences on the psychological adjustment of ethnic minority, low-SES adolescents. Journal of Adolescent Research, 18, 324-346.

http://dx.doi.org/10.1177/0743558403018004001

Wolf, D. L. (1997). Family secrets: Transnational struggles among children of Filipino immigrants. Sociological Perspectives, 40, 457-482. http://dx.doi.org/10.2307/1389452

Ying, Y.-W., \& Han, M. (2006). The effect of intergenerational conflict and school-based racial discrimination and depression and academic achievement in Filipino American adolescents. Journal of Immigrant and Refugee Studies, 4, 19-35.

http://dx.doi.org/10.1300/J500v04n04_03

Ying, Y.-W., \& Han, M. (2007). The longitudinal effect of intergenerational gap in acculturation on conflict and mental health in Southeast Asian American adolescents. The American Journal of Orthopsychiatry, 77, 61-66. http://dx.doi.org/10.1037/0002-9432.77.1.61 